\title{
Use of burn rice residues for production of nanosilica
}

\author{
(C) Duy Hung Nguyen, ${ }^{1 *}$ Liubov A. Zenitova, ${ }^{1+}$ Quang Dien Le, ${ }^{2}$ and Do Tien Thinh Bui ${ }^{2}$ \\ ${ }^{1}$ Kazan National Research Technological University. Karl Marx St., 72. Kazan, 420015. \\ Republic of Tatarstan. Russia. Phone: +7 (962) 550-46-19, (843)231-42-51. \\ E-mail:ndhungdt@gmail.com,liubovzenitova@mail.ru \\ ${ }^{2}$ Head of the Department of Cellulose and Paper Institute of Chemical Engineering. \\ Hanoi University of Technology. Dai Co Viet St., 01. Hai Ba Trung, Ha Noi, Viet Nam. \\ Phone:+84 386-849-55. Email: lequangdients@gmail.com,buidotienthinh@gmail.com
}

* Supervising author; ${ }^{+}$Corresponding author Keywords: rice straw, rice husk, hydrochloric acid, sulfuric acid, silica, oxygen, nanosilica.

\begin{abstract}
The current uilization of rice straw and husk as a solid fuel or burning out in the open air creates a large amount of ash, which is still inefficiently used and causes environmental problems in countries that grow rice. Meanwhile, valuable organic silica dioxide can be obtained from these wastes for wide applications. Recently, the production of organic silica dioxide from various sources has attracted much attention in the world. This article presents the results of a study on the preparation of nanosilica from rice straw and rice husk of Vietnamese by a two-stage process. In the first stage, burn rice straw or rice husks with ash content of $92.4 \%$ and $92.2 \%$ respectively, were treated by sodium hydroxide solution and then filtered to obtain a dissolved sodium silicate. In the second stage, the silica gel was precipitated from a solution by hydrochloric acid or sulfuric acid, the precipitate was washed, dried and burned at $575{ }^{\circ} \mathrm{C}$ to obtain the nanosilica powder. It was found that the treatment with $25 \% \mathrm{NaOH}$ at room temperature for 72 hours was optimal for extraction the maximum possible amount of silica from both types of silica sources. The highest yield of $\mathrm{SiO}_{2}$ is observed when $12 \% \mathrm{HCl}$ and $30 \% \mathrm{H}_{2} \mathrm{SO}_{4}$ were used, however, the maximum yield of $\mathrm{SiO}_{2}$ was achieved with using $12 \% \mathrm{HCl}$. The characterization of the nanosilica was carried out by SEM, EDS and XRD, which indicated the amorphous structure of obtained silica, which had particle diameter rang to 50 nanometers. The silica content of rice husk nanosilica powder was $54.8 \%$, it was $60.2 \%$ for rice straw nanosilica.
\end{abstract}

\section{References}

[1] J.-F. Chen, H.-M. Ding, J.-X. Wang, L. Shao. Preparation and characterization of porous hollow silica nanoparticles for drug delivery application. Biomaterials. 2004. Vol.25. P.723-727.

[2] Z. Luo, X. Cai, R.Y. Hong, L.S. Wang, W.G. Feng. Preparation of silica nanoparticles using silicon tetrachloride for reinforcement of PU. Chem. Eng. J. 2012. Vol.187. P.357-366.

[3] H.H.T. Van Hai Le, Chi Nhan Ha Thuc. Synthesis of silica nanoparticles from Vietnamese rice husk by sol-gel method. Nanoscale Res. Lett. 2013. Vol.8. P.58.

[4] N.H.D. My, P. Rutsaert, E.J. Van Loo, W. Verbeke. Consumers' familiarity with and attitudes towards food quality certifications for rice and vegetables in Vietnam. Food Control. 2017. Vol.82. P.74-82.

[5] U. Kumar, M. Bandyopadhyay. Fixed bed column study for Cd (II) removal from wastewater using treated rice husk. J. Hazard. Mater. 2006. Vol.129. P.253-259.

[6] A.S. Chukhno, I.B. Dmitrieva, V.A. Aksinovich, D.S. Silaeva, A.S. Senina, and A.A. Kergentsev. Electrosurface properties of silicon oxide(IV) in aqueous solutions of azoles. Butlerov Communications. 2014. Vol.38. No.5. P.78-83. ROI: jbc-02/14-38-5-78

[7] N.M. Hieu. Processes of thermal processing of rice husk in obtaining activated carbon material and their instrumental support: dissertation for the degree of candidate of technical sciences: spec. 05.17. 08, (2018).

[8] V.V. Kolpakova, G.N. Pankratov, A.A. Chevokin, Z.G. Skobelskaya, G.V. Semenov, V.V. Ananyev, I.A. Kirsch, N.D. Lukin, V.G. Kostenko, V.A. Shulyak. Food industry waste, a promising raw material for biodegradable packaging compositions. Food Industry. 2008. (russian)

[9] A. Nourbakhsh, F.F. Baghlani, A. Ashori. Nano-SiO ${ }_{2}$ filled rice husk/polypropylene composites: Physico-mechanical properties. Ind. Crops Prod. 2011. Vol.33. P.183-187.

[10] F. Ghorbani, A.M. Sanati, M. Maleki. Production of silica nanoparticles from rice husk as agricultural waste by environmental friendly technique. Environ. Stud. Persian Gulf. 2015. Vol.2. P.56-65.

[11] L.L. Osipovskaya, T.Yu. Surkov, A.K. Kojzhanova, B.M. Sukurov, D.M. Esimov. Extraction of noble

Kazan. The Republic of Tatarstan. Russia.

(C) Butlerov Communications. 2019. Vol.57. No.3. 

metals from man-made materials in the presence of rice husk. Chemical Technology. 2015. Vol.16. P.733738. (russian)

[12] A.N. Gabdullin, E.A. Nikonenko, V.F. Markov, T.M. Klyuev, and V.E. Tkacheva. Preparation of pure highly dispersed $\mathrm{SiO}_{2}$ from a silica residue. Butlerov Communications. 2017. Vol.50. No.4. P.90-95. DOI: $10.37952 /$ ROI-jbc-01/17-50-4-90

[13] V.V. Potapov, V.A. Sivashenko, and V.N. Zelenkov. Using of nanodispersed $\mathrm{SiO}_{2}$ in agriculture. Butlerov Communications. 2015. Vol.43. No.9. P.40-48. DOI: 10.37952/ROI-jbc-01/15-43-9-40

[14] E.V. Sayenko, N.B. Kondrashova, I.I. Lebedeva, and V.A. Valtsifer. Effect of temperature on the hydrothermal treatment textural characteristics of mesoporous silica. Butlerov Communications. 2011. Vol.25. No.6. P.128-131. ROI: jbc-02/11-25-6-128

[15] V.G. Ilves, M.G. Zuev, S.Yu. Sokovnin, A.M. Murzakayev. Properties of an amorphous nanopowder of silicon dioxide obtained by pulsed electron evaporation. Solid State Physics. 2015. Vol.57. P.24392445. (russian) 